\title{
Corrigendum: Differential gene and transcript expression analysis of RNA-seq experiments with TopHat and Cufflinks
}

Cole Trapnell, Adam Roberts, Loyal Goff, Geo Pertea, Daehwan Kim, David R Kelley, Harold Pimentel, Steven L Salzberg, John L Rinn \& Lior Pachter

Nat. Protoc. 7, 562-578 (2012); doi: 10.1038/nprot.2012.016; published online 1 March 2012; corrected after print 7 August 2014

In the version of this article initially published, the computer script in Box 1 sections B and C, and in Procedure Step 1, contained errors: the last section of the final three lines of the script had ' $\mathrm{C} 1$ ' where it should have been ' $\mathrm{C2}$ ', as follows:

C1_R1_2.fq should have been C2_R1_2.fq

C1_R2_2.fq should have been C2_R2_2.fq

C1_R3_2.fq should have been C2_R3_2.fq

Users are also directed to an official release version of Cufflinks (version 1.3.0) that produces nearly identical results to those shown in the manuscript, which were produced by Cufflinks 1.2.1 (an unofficial and undocumented development build that was the latest build available when the manuscript was originally written). The script in Procedure Step 16 and the data in Table 5 have been updated to reflect the output of version 1.3.0. The errors have been corrected in the HTML and PDF versions of the article.

\section{Corrigendum: Imaging pericytes and capillary diameter in brain slices and isolated retinae}

Anusha Mishra, Fergus M O’Farrell, Clare Reynell, Nicola B Hamilton, Catherine N Hall \& David Attwell Nat. Protoc. 9, 323-336 (2014); doi: 10.1038/nprot.2014.019; published online 16 January 2014; corrected after print 2 May 2014

In the version of this article initially published, the authors omitted the following from the acknowledgments: "We thank A. Nishiyama and D. Dietrich for providing NG2-DsRed mice". The error has been corrected in the HTML and PDF versions of the article.

\section{Erratum: Live imaging and quantitative analysis of gastrulation in mouse embryos using light-sheet microscopy and 3D tracking tools}

Takehiko Ichikawa, Kenichi Nakazato, Philipp J Keller, Hiroko Kajiura-Kobayashi, Ernst H K Stelzer, Atsushi Mochizuki \& Shigenori Nonaka

Nat. Protoc. 9, 575-585 (2014); doi:10.1038/nprot.2014.035; published online 13 February 2014; corrected after print 18 April 2014

In the version of this article initially published, Table 1 contained a number of errors: lateral resolution for two-photon was erroneously stated as ' $r$ divided by the square root of 2 ' instead of ' $r$ multiplied by the square root of 2 '; the illumination intensity for two-photon microscopy was given as ' $10^{3}$ times $E^{\prime}$ instead of ' $10^{6}$ times E'; 'lateral resolution' was assigned the incorrect footnote; and reference 11 was incorrectly cited as a source for the table. An additional footnote (a) has also been added to the version that was originally published. These errors have been corrected in the HTML and PDF versions of the article. 